Информация об авторах

Кружилин Иван Пантелеевич, академик РАН, доктор сельскохозяйственных наук, профессор, главный научный сотрудник ФГБНУ Всероссийский НИИ орошаемого земледелия (РФ 400002 , г. Волгоград, ул. Тимирязева, 9); тел. служебный 8(844) 260-24-36, vniioz2009@rambler.ru

Никольская Ольга Алексеевна, старший научный сотрудник лаборатории селекции, семеноводства и питомниководства Федерального научного центра агроэкологии, комплексных мелиораций и защитного лесоразведения РАН, (РФ, 400062, г. Волгоград, пр-т Университетский, 97.), аспирант ФГБОУ ВО Волгоградский государственный аграрный университет, тел. 8-927-256-58-09; LelkaNikolskaya@mail.ru \title{
RESULTS OF MOLECULAR-GENETIC STUDIES
OF THE BREEDING MATERIAL OF THE NEW GENERATION COTTON

\author{
V.A. Antonov ${ }^{1}$, O.Kh. Kimsanbaev ${ }^{2}$, I.Yu. Podkovyrov ${ }^{3}$, \\ S.A. Prikhodko ${ }^{3}$, D.S. Sharonov ${ }^{3}$ \\ ${ }^{I}$ Research Institute of Hygiene, Toxicology and Occupational Pathology \\ ${ }^{2}$ Ajlan and Bros. Holding group, Riyadh, Saudi Arabia \\ ${ }^{3}$ Volgograd State Agrarian University
}

DOI: 10.32786/2071-9485-2021-02-02

Received 26.10.2020

Submitted 12.04.2021

\begin{abstract}
Introduction. The use of molecular genetic methods in cotton plant breeding is an urgent task, which makes it possible to reduce the time for creating varieties with economically valuable traits. The emergence of new breeding samples of hybrid origin (PGSSH 1, PGSSH 7) with a long-day photoperiodic reaction, resistance to diseases and sucking pests, high quality fiber requires genetic research. Their comparison with breeding samples of semi-cultivated cotton (with green, red, gray fibers) makes it possible to reveal differences and identify genetic markers that ensure the realization of the biological potential of plant development. The purpose of our study was to identify genetic markers of economically valuable traits of cotton for the creation of a new generation of breeding material for the northern regions of cultivation based on the molecular genetic polymorphism of the DNA (Deoxyribonucleic acid) of the studied samples. For research, we have selected two of the most effective methods for assessing genetic polymorphism using DNA markers. The first of these is the method of SSR markers (English Simple Sequence Repeats), PCR (Polymerase chain reaction) with flanking primers to a short mini or microsatellite repeat. Another method using short random primers is RAPD analysis (Random Amplified Polymorphic DNA). Results and discussion. As a result of the study, it was found that SSR markers CM 129A-1, NAU-3299, SHIN-1409, BNL-299, TMB-0641, CGR-5238, CGR-5260, CGR-5249, CGR-5253 have the same indicators in all of the samples participating in the study, and only three markers (CM-43, CM-50, CGR-5264) show significant differences. Even in the varieties PGSSKh 1 and PGSSKh 7, which were obtained using the same breeding lines, these differences were found. As a result of the RAPD analysis using random primers (PR7, RA, Jeffreys, 33.15), 5 cotton genotypes were marked, for each of which a characteristic pattern was obtained - the RAPD spectrum. A total of 284 amplified markers were obtained for 5 cultivars. For several varieties, unique DNA fragments have been identified, which, most likely, can be considered species-specific, but in a certain combination can also be used as genus-specific markers. On average, for each primer, 17 marker DNA fragments were amplified for each cotton variety. The data obtained indicate that the most genetically distant variety is PGSSKh 7. The most closely related variety is PGSSKh1, which has a creamy fiber color and a variety with red fiber. These specimens are characterized by a short growing season of 110-115 days. As for the White and Green varieties, they are similar in fiber length and belong to the long-fiber group, and also have a longer growing season, ranging from 140 to 150 days. Variety PGSSH 7 is a new genetic donor of economically valuable traits. It is characterized by high yields, short growing periods and high quality fiber. Conclusions. Three microsatellite loci were found in the studied cotton varieties suitable for identification. The analyzed selection samples have both similar
\end{abstract}


and different DNA fragments. On their basis, it is possible to identify varieties that are promising for hybridization and accelerate the process of breeding work, and when using additional genotyping methods, in the future, it is possible to trace the process of inheritance of economically valuable traits in offspring. The results obtained in this work are of practical value for certification and identification of the studied varieties on the basis of their identified genetic characteristics.

Key words: cotton (Gossypium), RAPD analysis, microsatellite analysis, primer, genetic markers, breeding.

Citation. Antonov V.A., Kimsanbaev O.Kh., Podkovyrov I.Yu., Prikhodko S.A., Sharonov D.S. Results of molecular-genetic studies of the breeding material of the new generation cotton. Proc. of the Lower Volga Agro-University Comp. 2021. 2(62). 22-32 (in Russian). DOI: 10.32786/2071-94852021-02-02.

Author's contribution. All authors of this research paper have directly participated in the planning, execution, or analysis of this study. All authors of this paper have read and approved the final version submitted.

Conflict of interest. The authors declare no conflict of interest.

\title{
УДК 577.2:633.511:631.526.32 \\ РЕЗУЛЬТАТЫ МОЛЕКУЛЯРНО-ГЕНЕТИЧЕСКИХ ИССЛЕДОВАНИЙ СЕЛЕКЦИОННОГО МАТЕРИАЛА ХЛОПЧАТНИКА НОВОГО ПОКОЛЕНИЯ
}

\author{
В. А. Антонов ${ }^{1}$, доктор медицинских наук, и.о. директора \\ О. Х. Кимсанбаев ${ }^{2}$, доктор сельскохозяйственных наук, профессор \\ И. Ю. Подковыров ${ }^{3}$, кандидат сельскохозяйственных наук, доиент \\ С. А. Приходько ${ }^{3}$, ведущчий спещчиалист \\ Д. С. Шаронов ${ }^{3}$, стариий лаборант \\ ${ }^{l}$ ФГУП Научно-исследовательский институт гигиены, токсикологии и профпатологии, \\ 2. Волгоград, Россия \\ ${ }^{2}$ «Ajlan and Bros. Holding group», Эр-Рияд, Саудовская Аравия \\ ${ }^{3}$ Волгоградский государственный аграрный университет, г. Волгоград
}

Дата поступления в редакцию 26.10.2020

Дата принятия к печати 12.04.2021

Актуальность. Применение в селекции растений хлопчатника молекулярногенетических методов является актуальной задачей, позволяющей сократить время создания сортов с хозяйственно ценными признаками. Появление новых селекционных образцов гибридного происхождения (ПГССХ 1, ПГССХ 7) с длиннодневной фотопериодической реакцией, устойчивостью к болезням и сосущим вредителям, волокном высокого качества требует генетических исследований. Их сравнение с селекционными образцами полукультурного хлопчатника (с волокном зеленого, рыжего, серого цветов) позволяет выявить различия и выявить генетические маркеры, обеспечивающие реализацию биологического потенциала развития растений. Целью нашего исследования являлось выявление генетических маркеров хозяйственно ценных признаков хлопчатника для создания селекционного материала нового поколения для северных регионов культивирования на основе молекулярно-генетического полиморфизма ДНК исследуемых образцов. Для исследований нами были выбраны два наиболее эффективных метода оценки генетического полиморфизма с использованием ДНК-маркеров. Первым из них является метод SSR-маркеров (англ. Simple Sequence Repeats), ПЦР с флангирующими праймерами к короткому мини- или микросателлитному повтору. Другой метод с использованием коротких произвольных праймеров - RAPD-анализ (англ. Random Amplified Polymorphic DNA). Результаты и обсуждение. В результате исследования установлено, что SSR-маркеры CM 129A-1, NAU-3299, SHIN-1409, BNL-299, TMB-0641, CGR-5238, CGR-5260, CGR-5249, CGR5253 имеют одинаковые показатели у всех образцов, участвующих в исследовании, и только в трёх маркерах (CM-43, CM-50, CGR-5264) наблюдаются значимые различия. Даже у сортов ПГССХ 1 и ПГССХ 7, которые были получены в результате использования одних и тех же се- 
лекционных линий, были обнаружены эти различия. В результате проведенного RAPD анализа с использованием произвольных праймеров (PR7, RA, Jeffreys, 33.15) было маркировано 5 генотипов хлопка, для каждого из которых был получен характерный паттерн - RAPD спектр. B общей сложности для 5 сортов было получено 284 амплифицированных маркера. Для нескольких сортов определены уникальные ДНК-фрагменты, которые, по всей видимости, можно считать видоспецифичными, но в определенном сочетании могут быть использованы и в качестве родоспецифичных маркеров. В среднем по каждому праймеру апмлифицировано по 17 маркерных фрагментов ДНК для каждого сорта хлопка. Полученные данные свидетельствуют о том, что наиболее генетически отдалённым является сорт ПГССХ 7. Наиболее близкородственными являются сорт ПГССХ1, отличительной чертой которого является кремовый цвет волокна, и сорт с рыжим волокном. Эти образцы отличаются коротким периодом вегетации - 110-115 дней. Что касается сортов Белый и Зелёный, то они сходны по длине волокна и относятся к длинноволокнистой группе, а также имеют более длительный период вегетации, варьирующий от 140 до 150 дней. Сорт ПГССХ 7 является новым генетическим донором хозяйственно ценных признаков. Он отличается повышенной урожайностью, коротким периодом вегетации и волокном высокого качества. Выводы. Найдены три микросателлитных локуса у исследованных сортов хлопчатника, пригодных для идентификации. Анализируемые селекционные образцы имеют как сходные, так и различающиеся фрагменты ДНК. На их основе возможно выявление перспективных для гибридизации сортообразцов и ускорение процесса селекционной работы, а при использовании дополнительных методов генотипирования в перспективе можно проследить процесс наследования хозяйственно ценных признаков у потомства. Результаты, полученные в данной работе, представляют практическую ценность для паспортизации и идентификации исследуемых сортов на основе их выявленных генетических особенностей.

Ключевые слова: хлопчатник (Gossypium), RAPD анализ, микросателлитный анализ, праймеры, генетические маркеры, селекиия хлопчатника.

Цитирование. Антонов В.А., Кимсанбаев О.Х., Подковыров И.Ю., Приходько С.А., Шаронов Д.С. Результаты молекулярно-генетических исследований селекционного материала хлопчатника нового поколения. Известия НВ АУК. 2021. 2(62). 22-32. DOI: 10.32786/2071-9485-2021-02-02.

Авторский вклад. Все авторы настоящего исследования принимали участие в планировании, выполнении или анализе данного исследования. Все авторы настоящей статьи ознакомились и одобрили представленный окончательный вариант.

Конфликт интересов. Авторы заявляют об отсутствии конфликта интересов.

Введение. При исследовании геномов растений у ученых и селекционеров возникает гораздо больше трудностей, чем при исследовании геномов других живых организмов $[1,2]$. Помимо огромных размеров геномов растений, которые достигают для отдельных видов растений сотни миллиардов пар нуклеотидов, существует и масса других обстоятельств, усложняющих эту проблему. К ним можно отнести: резкое колебание числа хромосом, трудность хромосомного картирования отдельных генов, длительный процесс размножения большинства растений, что, в свою очередь, замедляет их генетический анализ, а также из-за отсутствия возможности выделения индивидуальных хромосом в чистом виде, методами, которые обычно применяют для получения хромосом человека или животного, и многие другие факторы, описанные в литературе [3].

Хлопчатник (лат. Gossypium) является одной из ведущих и важных сельскохозяйственных культур России $[5,13]$. Изучение генома этой культуры создает большие перспективы для улучшения хозяйственноценных признаков производимых сортов при помощи молекулярных методов и селекции $[6,11]$. Селекция по своей сути является непрерывным процессом, ведь возрастающие требования к качеству и, что самое главное, количеству продукции, мотивируют на постоянное обновление сортов этой куль- 
туры, делают их более устойчивыми к проблемам фитопатогенного характера, а также устойчивыми к местным климатическим особенностям регионов страны. Важность этой культуры трудно переоценить: это растение в прямом смысле слова одевает едва ли не половину мира, и, помимо текстильной индустрии, волокна этого растения используют для изготовления различных взрывчатых веществ [7]. Создание новых устойчивых к болезням сортов с комплексом хозяйственно ценных качеств является актуальной задачей $[8,9,10]$. Традиционные методы селекции, основанные на фенотипическом сходстве и отличии, используются и по сей день, поскольку их анализ не требует сложных методик и дорогостоящего оборудования, но на данный момент все большую популярность набирают современные методы, основанные на полиморфизме нуклеотидных последовательностей ДНК с применением ДНК-маркеров (RAPD, SSR, ISSR). Маркеры, в свою очередь, нашли широкое применение в получении молекулярногенетических характеристик гибридов, а также их родительских форм. Наиболее надежными являются SSR-маркеры, основанные на полиморфизме длины коротких повторов (микросателлитов), разбросанных по всему геному, а также RAPD-метод, который прост в исполнении и при правильном подборе праймеров и стандартизации метода обладает высокой информативностью. По сравнению с фенотипическими признаками ДНК-маркеры стабильны, хорошо воспроизводимы и не зависят от влияния факторов окружающей среды $[11,12]$.

Целью нашего исследования являлось выявление генетических маркеров хозяйственно ценных признаков хлопчатника для создания селекционного материала нового поколения для северных регионов культивирования на основе молекулярногенетического полиморфизма ДНК исследуемых образцов.

Материалы и методы. В качестве предмета исследований был использован растительный материал пяти сортов хлопчатника селекции учёных Волгоградского ГАУ (Белый, Зеленый, Рыжий, ПГССХ-1, ПГССХ-7).

Для исследования мы выбрали два наиболее эффективных метода оценки генетического полиморфизма с помощью ДНК-маркеров [11]. Первым из них является метод SSR-маркеров (англ. Simple Sequence Repeats), ПЦР с фланговыми праймерами к короткому мини- или микросателлитному повтору. По сравнению с другими методами (RAPD и ISSR) использование маркеров SSR обеспечивает высокую надежность и воспроизводимость результатов, однако одна пара флангирующих праймеров позволяет рассмотреть полиморфизм только одного локуса. Проявление кодоминантного характера этих маркеров позволяет различить гетеро- и гомозиготные растения на ранних стадиях развития, что значительно экономит время при получении новых сортов и гибридов. Нередки случаи, когда полиморфизм невозможно обнаружить во многих исследуемых локусах, как правило, эти последовательности являются видоспецифичными для данного микросателлитного локуса. Переживая генетические изменения, эти последовательности мутируют в несколько сотен раз чаще, чем структурированные гены, и указывают на высокий уровень полиморфизма через изменение их длины и расположения. Второй, самый распространенный и простой в исполнении метод, это RAPD-типирование (Random Amplified Polymorphic DNA), полимеразная цепная реакция с использованием одиночных и коротких, чаще всего 10-членных праймеров с произвольной нуклеотидной последовательностью. Молекулярные маркировки методом RAPD особенно эффективны в отношении видов со слабыми межсортовыми различиями, включая хлопок.

Последовательность праймеров не является абсолютно любой, как правило, преимущественно предпочтительной является последовательность богатая GC составляющей, в диапазоне 40-70 \% и 50-100 \% лингвистической сложности нуклеотидной после- 
довательности. Еще одним преимуществом этого метода является то, что он позволяет использовать как одиночный праймер, так и несколько пар праймеров. RAPD-продукты формируются в результате амплификации фрагментов геномной ДНК, фланкированной инвертированной последовательностью используемого праймера. RAPD-метод по своей технологии является универсальным для изучения различных видов, ведь, как правило, праймер, отображающий высокий полиморфизм для одного вида, будет эффективен и для других генотипов. Оба описанных выше метода позволяют производить как подбор родительских пар для скрещивания, так и проводить идентификацию для дальнейшей паспортизации сортов.

Методика молекулярно-генетического анализа селекционного материала хлопка включала несколько этапов.

Экстракция ДНК. Материалом исследования послужили первые истинные листья ростков хлопчатника. Выделение ДНК из исследуемых образцов производили с использованием комплекта реагентов «Проба-ЦТАБ» (ООО «АгроДиагностика», Россия). С целью получения статистически значимых результатов в исследовательской работе были использованы образцы от 10 растений каждого изучаемого сорта. Полимеразную цепную реакцию проводили с олигонуклеотидными праймерами, синтезированными в НПК «Синтол» (Россия, г. Москва).

Амплификация ДНК. Для фрагментного анализа микросателлитов была проведена амплификация ДНК с использованием термоциклера «Терцик» поризводства ООО ДНК-Технология (Россия, г. Москва). Продолжительность ПЦР составила 30 циклов, была применена процедура горячего старта. Объем ПЦР-смеси составил 25 мкл. Реакционная ПЦР-смесь имела следующий состав: dNTP - 0,25 мM; MgCl2 - 1,5 мM; Taqполимераза - 1 единица; праймеры - 0,12 мкМ (каждого); ПЦР-буфер; ДНК исследуемого образца - 100 нг. Минеральное масло было наслоено на поверхность амплификационной смеси в количестве 30 мкл. Для проведения ПЦР был выбран оптимальный температурный режим: шаг денатурации - при t $95{ }^{\circ} \mathrm{C}$ в течение 1 мин $\left(95{ }^{\circ} \mathrm{C}\right.$ на протяжении 10 сек; этап отжига праймеров - $60^{\circ} \mathrm{C}$ продолжительностью 10 сек; шаг элонгации (синтеза) цепи $-72{ }^{\circ} \mathrm{C}$ в течение 10 сек), финальная полимеризация цепей ДНК при $\mathrm{t} 72{ }^{\circ} \mathrm{C}$ на протяжении 3 мин. Исследование флуоресцентно-меченных ампликонов были проведены на базе НПК «Синтол» (Россия, г. Москва) методом капиллярного электрофореза.

Для проведения RAPD-анализа также была проведена амплификация ДНК с использованием термоциклера «Терцик» поризводства ООО ДНК-Технология (Россия, г. Москва). В данном случае продолжительность ПЦР составила 45 циклов (был применен «Горячий старт»). Объем ПЦР-смеси составил 25 мкл. Амплификационная смесь имела следующий состав: dNTP - 0,2 мM; MgCl2 - 2,5 мM; Таq-полимераза - 1 единица; праймеры - 0,10 мкМ (каждого); ПЦР-буфер; ДНК исследуемого образца - 100 нг. Для проведения ПЦР был выбран следующий температурный режим: шаг денатурации при t $95{ }^{\circ} \mathrm{C}$ в течение 5 мин $\left(95{ }^{\circ} \mathrm{C}\right.$ на протяжении 30 сек; этап отжига праймеров - $36{ }^{\circ} \mathrm{C}$ продолжительностью 30 сек; шаг элонгации (синтеза) цепи $-72{ }^{\circ} \mathrm{C}$ в течение 2 мин), финальная полимеризация цепей ДНК - при $\mathrm{t} 72^{\circ} \mathrm{C}$ на протяжении 7 мин. При электрофоретическом разделении нуклеиновых кислот в агарозном геле была применена стандартная методика [11].

Анализ данныхx. Размер фрагментов ДНК, полученных в ходе осуществления микросателлитного анализа, был проанализирован с помощью программного обеспечения Peak Scanner Software v1.0. При детектировании ПЦР-продукта, предназначенного для RAPDанализа, проводили разделение ДНК фрагментов электрофорезным методом ДНК в 3 \% 


\section{***** HЗBECTYЯ ***** \\ НИЖНЕВОАЖСКОГО АГРОУНИВЕРСИТЕТСКОГО КОМПАЕКСА:

агарозном геле, для приготовления которого использовали трис-боратный буфер при градиенте напряжения 5B/см. После электрофореза производили съемку подкрашенного этидиум-бромидом геля при помощи гель-документирующей системы «GelDoc EZ» (Bio-Rad Laboratories, Inc. CШA). Для RAPD-анализа были построены бинарные матрицы по каждому из праймеров. Кластерный анализ и построение дендрограмм проводили с помощью программного обеспечения DARwin 6.lnk на основании метода ближайшего соседа (Neighbor Joining) как для фрагментного анализа, так и для RAPD-анализа.

Результаты и обсуждение. Метод микросателлитного анализа позволяет стандартизовать и сопоставлять результаты, полученные в различных лабораториях, при условии использования идентичных хромосомных локусов. Данное исследование направлено на оценку степени генетического разнообразия и в дальнейшем с возможностью паспортизации сортов хлопка местной селекции. Из литературных источников нами были отобраны 12 микросателлитных маркеров, а также 4 пары праймеров, предназначенных для RAPD-типирования, которые позволяют надежно различать и идентифицировать сорта по генетических признакам.

Взятые нами SSR-маркеры находятся на разных хромосомах, что, в свою очередь, делает анализ более надежным и информативным. Так, из 12 использованных пар праймеров полиморфные участки удалось выявить по 3 ДНК-фрагментам. В сумме для группы образцов обнаружены 22 аллели для 12 SSR-маркеров. Данные анализа представлены в виде таблицы (таблица 1).

Таблица 1 - Результаты анализа 5 генотипов хлопчатника с применением SSR-маркеров

Table 1 - Results of analysis of 5 cotton genotypes using SSR markers

\begin{tabular}{|c|c|c|c|c|c|c|}
\hline $\begin{array}{c}\text { Наименование } \\
\text { образца / Sample } \\
\text { name }\end{array}$ & $\begin{array}{c}\text { SSR- } \\
\text { праймер / } \\
\text { SSR- } \\
\text { primer }\end{array}$ & $\begin{array}{l}\text { 1. Рыжий / } \\
\text { Ginger }\end{array}$ & $\begin{array}{l}\text { 2. Белый / } \\
\text { White }\end{array}$ & $\begin{array}{l}\text { 3. Зеленый / } \\
\text { Green }\end{array}$ & $\begin{array}{l}\text { 4. ПГССХ } 1 \\
\text { / PGSSH } 1\end{array}$ & $\begin{array}{c}\text { 5. ПГССХ } 7 \text { / } \\
\text { PGSSH } 7\end{array}$ \\
\hline \multirow{12}{*}{$\begin{array}{c}\text { Размер продук- } \\
\text { тов амплифика- } \\
\text { ции в п.н. в ре- } \\
\text { зультате приме- } \\
\text { нения SSR- } \\
\text { маркеров / } \\
\text { Amplification } \\
\text { products size in } \\
\text { bp. as a result of } \\
\text { using SSR } \\
\text { markers }\end{array}$} & $\begin{array}{c}\text { CM 129A- } \\
1\end{array}$ & 64 & 64 & 64 & 64 & 64 \\
\hline & CM 43 & $103 / 118$ & 110 & 110 & $103 / 118$ & $103 / 110$ \\
\hline & CM 50 & 166 & 166 & 166 & 164 & 164 \\
\hline & NAU 3299 & 180 & 180 & 180 & 180 & 180 \\
\hline & SHIN-1409 & 198 & 198 & 198 & 198 & 198 \\
\hline & BNL 299 & $126 / 130$ & $126 / 130$ & $126 / 130$ & $126 / 130$ & $126 / 130$ \\
\hline & TMB 641 & 213 & 213 & 213 & 213 & 213 \\
\hline & CGR 5238 & $175 / 190$ & $175 / 190$ & $175 / 190$ & $175 / 190$ & $175 / 190$ \\
\hline & CGR 5260 & $109 / 124$ & $109 / 124$ & $109 / 124$ & $109 / 124$ & $109 / 124$ \\
\hline & CGR 5249 & 129 & 129 & 129 & 129 & 129 \\
\hline & CGR 5264 & $133 / 142$ & 142 & 142 & $133 / 142$ & 142 \\
\hline & CGR 5253 & $121 / 132$ & $121 / 132$ & $121 / 132$ & $121 / 132$ & $121 / 132$ \\
\hline
\end{tabular}

В результате исследования установлено, что SSR-маркеры CM 129A-1, NAU 3299, SHIN 1409, BNL 299, TMB 0641, CGR 5238, CGR 5260, CGR 5249, CGR 5253 имеют одинаковые показатели у всех образцов, участвующих в исследовании, и только в трёх маркерах (CM 43, CM 50, CGR 5264) наблюдаются значимые различия. Даже у сортов ПГССХ 1 и ПГССХ 7, которые были получены в результате использования одних и тех же селекционных линий были обнаружены эти различия. На основании величин генетических расстояний, полученных после микросателлитного анализа, на основе метода «Neighbor Joining» была построена дендрограмма генетических взаимоотношений при помощи программы DARwin 6.lnk (рисунок 1). 


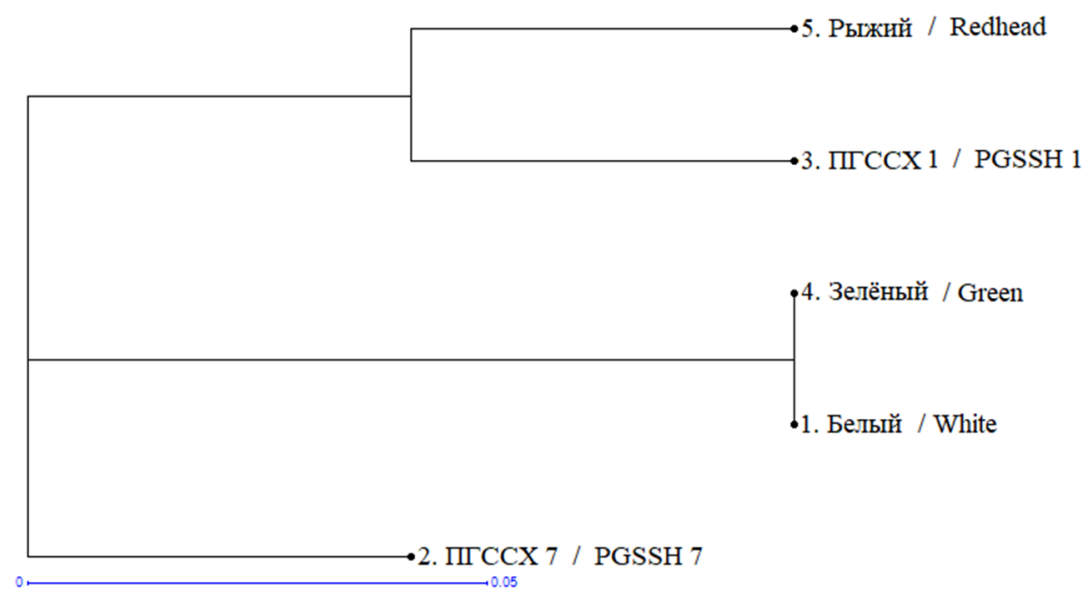

Рисунок 1 - Дендрограмма генетических взаимодействий, построенная на основании величин генетических дистанции, рассчитанных по распределению SSR-маркеров в 5 генотипах хлопка: 1 - Белый; 2 - ПГССХ-7; 3 - ПГССХ-1; 4 - Зелёный; 5 - Рыжий

Figure 1 - Dendrogram of genetic interactions based on the values of genetic distances calculated from the distribution of SSR markers in 5 cotton genotypes:

1 - White; 2 - PGSSH-7; 3 - PGSSH-1; 4 - Green; 5 - Redhead

Для проведения RAPD-анализа из литературных источников нами были отобраны 4 высокоспецифичных пар праймеров (PR7, RA, Jeffreys, 33.15), последовательность которых представлена в таблице 3 [3]. При анализе RAPD-профилей исследуемых сортов хлопка было обнаружено, что сорта имеют как общие видоспецифические, так и вариабельные фрагменты, по которым возможно дифференцировать сорта друг от друга. По каждому из праймеров были составлены бинарные матрицы с последующей обработкой содержащихся в них данных.

Таблица 2 - Характеристика выбранных праймеров для идентификации культурных сортов хлопка методом RAPD

Table 2 - Characteristics of selected primers for identification of cotton cultivars by RAPD method

\begin{tabular}{|c|c|c|c|}
\hline № & $\begin{array}{c}\text { Обозначение / } \\
\text { name }\end{array}$ & $\begin{array}{c}\text { Последовательность / } \\
\text { Sequence }\end{array}$ & $\begin{array}{c}\text { Температура отжига / } \\
\text { Annealing temperature }\end{array}$ \\
\hline 1 & PR-7 & 5' - CAG CCC AGA G - 3' & 36 \\
\hline 2 & RA & 5'- GTT TCG CTC C -3' & 36 \\
\hline 3 & Jeffreys & 5'- GGA GGT GGG CAG GAN G -3' & 36 \\
\hline 4 & 33.15 & 5'-AGA GGT GGG CAG GTG G -3' & 36 \\
\hline
\end{tabular}

B результате проведенного RAPD-анализа с использованием произвольных праймеров (PR7, RA, Jeffreys, 33.15) было маркировано 5 генотипов хлопка, для каждого из которых был получен характерный паттерн - RAPD спектр. В общей сложности для 5 сортов было получено 284 амплифицированных маркеров. Для нескольких сортов определены уникальные ДНК-фрагменты, которые, по всей видимости, можно считать видоспецифичными, но в определенном сочетании могут быть использованы и в качестве родоспецифичных маркеров. В среднем по каждому праймеру апмлифицировано по 17 маркерных фрагментов ДНК для каждого сорта хлопка.

С помощью компьютерной обработки по методу кластерного анализа «Neighbor Joining» на основании фрагментов RAPD-спектров была построена дендрограмма генетического сходства исследованных сортов хлопка (рисунок 2). 


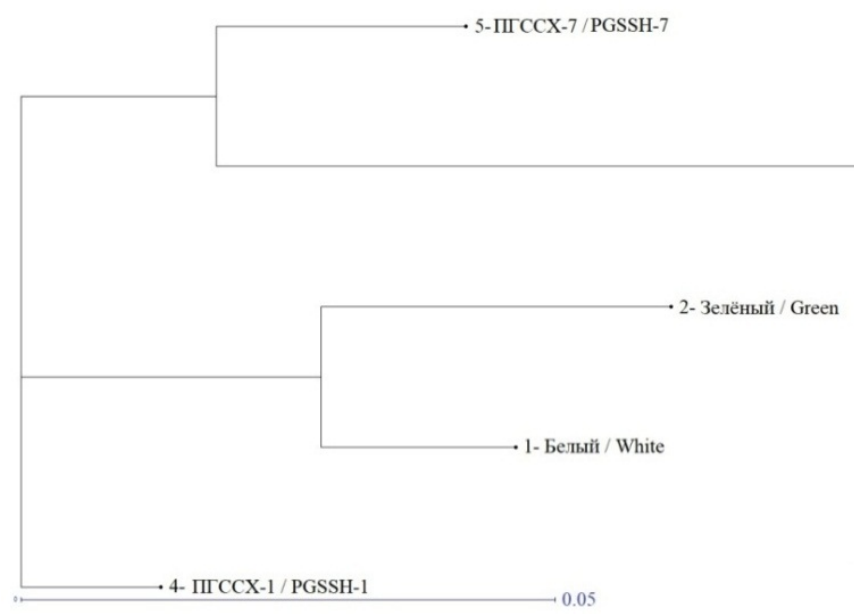

Рисунок 2 - Дендрограмма генетических расстояний исследуемых сортов хлопчатника, полученная с использованием метода иерархического кластерного анализа: 1 - Белый; 2 - Зелёный; 3 - Рыжий; 4 - ПГССХ-1; 5 - ПГССХ-7

Figure 2 - Dendrogram of genetic distances of the studied cotton varieties obtained using the method of hierarchical cluster analysis:

1 - White; 2 - Green; 3 - Redhead; 4 - PGSSH-1; 5 - PGSSH-7

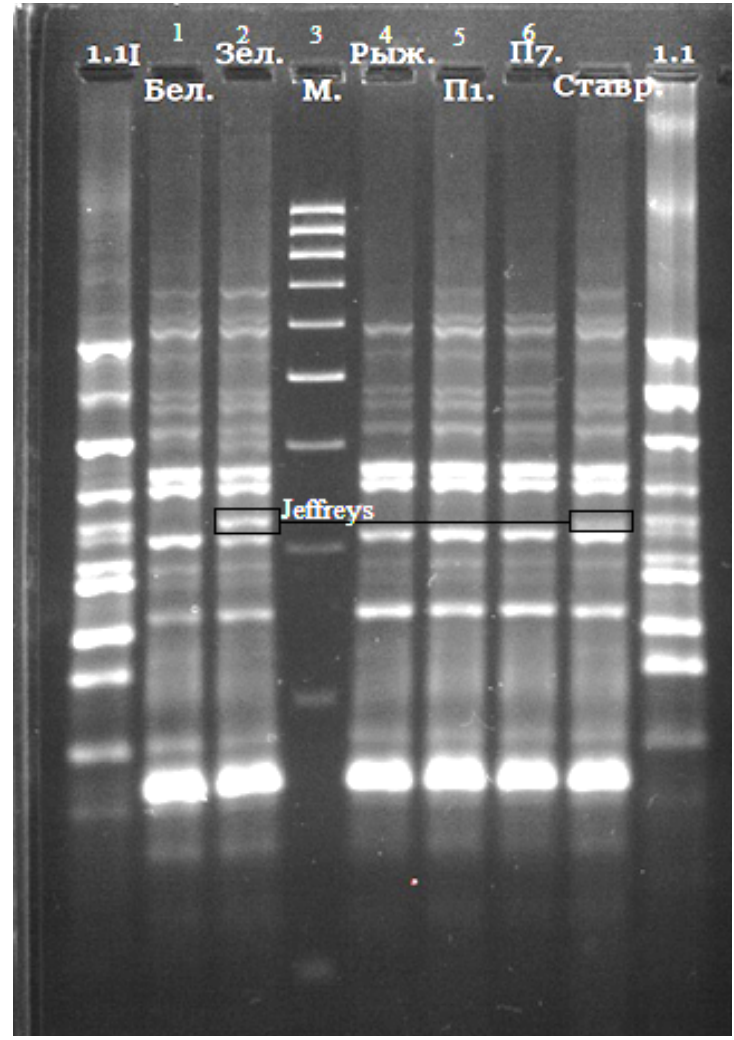

Рисунок 3 - Электрофореграмма RAPD-фрагментов сортов хлопка, полученных после амплификации ДНК с использованием праймера Jeffreys: Выделенные фрагменты видоспецифичны:

1 - Белый; 2 - Зелёный; 3 - Маркер длин 100-1000; 4 - Рыжий; 5 - ПГССХ-1; 6 - ПГССХ-7

Figure 3 - Electrophoregram of RAPD fragments of cotton varieties obtained after DNA amplification using Jeffreys primer: The selected fragments is species-specific:

1 - White; 2 - Green; 3 - Marker of lengths 100-1000; 4 - Redhead; 5 - PGSSH-1; 6 - PGSSH-7 
Полученные данные свидетельствуют о том, что из всех исследуемых сортов наиболее генетически отдалённым является сорт ПГССХ 7. Наиболее близки между собой сорт ПГССХ 1 и хлопчатник с рыжим волокном. Эти образцы отличаются коротким периодом вегетации - 110-115 дней. Белый и зелёный образцы сходны по длине волокна. Они относятся к длинноволокнистой группе и имеют длительный период вегетации 140-150 дней. Сорт ПГССХ 7 является новым генетическим донором хозяйственно ценных признаков. Он отличается повышенной урожайностью коротким периодом вегетации и волокном высокого качества.

Выводы. Таким образом, в результате проведенного исследования определены 3 микросателлитных локуса, пригодных для идентификации исследуемых генотипов хлопчатника. Для нескольких сортов определены уникальные RAPD-фрагменты, которые, по всей видимости, можно считать видоспецифическими маркерами. Выявлено, что праймер Jeffreys оказался наиболее предпочтительным для внутривидового типирования хлопчатника. При использовании кластерного анализа удалось сформировать отдельные группы для всех сортов, которые в свою очередь позволяют наглядно отобразить степень сходства (генетическую дистанцию) исследуемых образцов. Следует отметить, что, несмотря на выявленные отличия, сорта волгоградской коллекции имели более высокую степень родства. Полученная база данных может быть использована для паспортизации и идентификации исследуемых сортов на основе их выявленных генетических особенностей.

На основе полученных данных установлено, что анализируемые селекционные образцы имеют как сходные, так и различающиеся фрагменты ДНК. На их основе возможно выявление перспективных для гибридизации сортообразцов и ускорение процесса селекционной работы, а при использовании дополнительных методов генотипирования в перспективе можно проследить процесс наследования хозяйственно ценных признаков у потомства. Результаты, полученные в данной работе, представляют практическую ценность для паспортизации и идентификации исследуемых сортов на основе их выявленных генетических особенностей. Совершенствование метода молекулярно-генетического анализа селекционного материала хлопчатника позволит выявить генетические маркеры для быстрой оценки новых генотипов при подборе пар для гибридизации. Для выявления более тонких генетических характеристик при формировании маркер-ориентированной селекции хлопчатника необходимо проведение дополнительных генотипических исследований с расширением числа генетических локусов и ДНК-маркеров.

\section{Библиографический список}

1. Баймухаметова Э. А. Применение индуцированного мутагенеза для увеличения генетического полиморфизма хлопчатника // Биомика. 2017. Т. 9. № 4. С. 370-379.

2. Баймухаметова Э. А. Хлопчатник: особенности культуры, перспективы создания трансгенных отечественных сортов и их выращивания в России // Биомика. 2016. Т. 8. № 3. С. 275-288.

3. Мамедова Н. Х., Шихлинский Г. М. Фитопатологическая устойчивость к Verticillium dahliae мутантов и гибридов хлопчатника // Новые и нетрадиционные растения и перспективы их использования. 2015. С. 339-342.

4. Подковыров И. Ю., Ермак Д. Ю. Потенциал засухоустойчивости хлопчатника сорта ПГССХ 1 в условиях светло-каштановых почв // Вестник Донского государственного аграрного университета. 2020. № 1 (35). С. 26-29.

5. Ходжаев Т. А. Повышение посевных качеств семян хлопчатника под действием нейтронного облучения // Известия ВУЗов Кыргызстана. 2015. № 9. С. 12-14.

6. Эгамова Н. Б., Бондарчук М. М. Анализ современных селекционных сортов хлопка Республики Узбекистан: научные исследования 2016. Московский государственный университет дизайна и технологии, 2016. 
7. Genetic diversityanalysis in 27 tomato accessions using morphological andmolecular markers / Catur Herison, Surjono H. Sutjahjo, Ineu Sulastrini, Rustikawati Rustikawati, Siti Marwiyah // AGRIVITA, Journal of AgriculturalScience. 2018. V. 40 (1). P. 36-44.

8. Ghaffar Kiani, Mohammad Siahchehreh Geneticdiversity in tomato varieties assessed by ISSR markers // International Journal of Vegetable Science. 2017.

9. Glinushkin A. P., Startsev V. I., Startseva L. V. Biological Aspects of Economic Efficiency of Crop Farming // IOP Conference Series: Earth and Environmental Science, 2020.

10. Kiseleva M. I., Ovsyankina A. V., Kolomiets T. M. Some aspects of the distribution of Fusarium on cereals of Russia // Acta Phytopathologica et Entomologica Hungarica. 2016. V. 51(2). P. 183-192.

11. Ovchinnikov A. S., Kimsanbaev O. H., Antonov V. A. Agrobiological assessment of cotton breeding material in light chestnut soils // E3S Web of Conferences. 2020. V. 203. 02010. https://doi.org/10.1051/e3sconf/202020302010.

\section{References}

1. Bajmuhametova Je. A. Primenenie inducirovannogo mutageneza dlya uvelicheniya geneticheskogo polimorfizma hlopchatnika // Biomika. 2017. T. 9. № 4. P. 370-379.

2. Bajmuhametova \}. A. Hlopchatnik: osobennosti kul'tury, perspektivy sozdaniya transgennyh otechestvennyh sortov i ih vyraschivaniya v Rossii // Biomika. 2016. T. 8. № 3. P. 275-288.

3. Mamedova N. H., Shihlinskij G. M. Fitopatologicheskaya ustojchivost' k Verticillium dahliae mutantov i gibridov hlopchatnika // Novye i netradicionnye rasteniya i perspektivy ih ispol'zovaniya. 2015. P. 339-342.

4. Podkovyrov I. Yu., Ermak D. Yu. Potencial zasuhoustojchivosti hlopchatnika sorta PGSSX $1 \mathrm{v}$ usloviyah svetlo-kashtanovyh pochv // Vestnik Donskogo gosudarstvennogo agrarnogo universiteta. 2020. № 1 (35). P. 26-29.

5. Hodzhaev T. A. Povyshenie posevnyh kachestv semyan hlopchatnika pod dejstviem nejtronnogo oblucheniya // Izvestiya VUZov Kyrgyzstana. 2015. № 9. P. 12-14.

6. Jegamova N. B., Bondarchuk M. M. Analiz sovremennyh selekcionnyh sortov hlopka Respubliki Uzbekistan: nauchnye issledovaniya 2016. Moskovskij gosudarstvennyj universitet dizajna i tehnologii, 2016.

7. Genetic diversityanalysis in 27 tomato accessions using morphological andmolecular markers / Catur Herison, Surjono H. Sutjahjo, Ineu Sulastrini, Rustikawati Rustikawati, Siti Marwiyah // AGRIVITA, Journal of AgriculturalScience. 2018. V. 40 (1). P. 36-44.

8. Ghaffar Kiani, Mohammad Siahchehreh Geneticdiversity in tomato varieties assessed by ISSR markers // International Journal of Vegetable Science. 2017.

9. Glinushkin A. P., Startsev V. I., Startseva L. V. Biological Aspects of Economic Efficiency of Crop Farming // IOP Conference Series: Earth and Environmental Science, 2020.

10. Kiseleva M. I., Ovsyankina A. V., Kolomiets T. M. Some aspects of the distribution of Fusarium on cereals of Russia // Acta Phytopathologica et Entomologica Hungarica. 2016. V. 51(2). P. 183-192.

11. Ovchinnikov A. S., Kimsanbaev O. H., Antonov V. A. Agrobiological assessment of cotton breeding material in light chestnut soils // E3S Web of Conferences. 2020. V. 203. 02010. https://doi.org/10.1051/e3sconf/202020302010.

\section{Author's Information}

Antonov Valery Alekseevich, acting Director of the Research Institute of Hygiene, Toxicology and Occupational Pathology (Russian Federation, 400048, Volgograd, street named after Zemlyachka, 12), Doctor of Medical Sciences, tel. 8 (8442) 78-62-57, email: antonov@,rihtop.ru

Kimsanbaev Oybek Khuzhamuratovich, expert on regional development of projects of the company "Ajlan and Bros. Holding group ". United Arab Emirates, (United Arab Emirates, Unit 03-OF-02-03-OF-18, Level 3, Gate Village Building 08, Dubai International Financial Center, Dubai) Doctor of Agricultural Sciences, Professor, tel. +966545101367, e-mail: newsbek@mail.ru

Podkovyrov Igor Yurievich, Associate Professor at the Department of Horticulture, Breeding and Seed Production, Volgograd State Agrarian University (RF, 400002, Volgograd, Prospect Universitetsky, 26), tel. 8 (8442) 41-17-75, email: agrosad@inbox.ru 


\title{
***** H3BECTYЯ ***** \\ НИЖНЕВОАЖСКОГО АГРОУНИВЕРСИТЕТСКОГО КОМПАЕКСА \\ НАУКА И ВЫСШЕЕ ПРОФЕССИОНААЬНОЕ ОБРАЗОВАНИЕ
}

Prikhodko Svetlana Alekseevna, Leading Specialist of the Scientific and Educational Center for Molecular Genetic Technologies, Volgograd State Agrarian University (RF, 400002, Volgograd, Prospect Universitetsky, 26), tel. 8 (961) 679-07-22, email: bobls@mail.ru

Sharonov Dmitry Sergeevich, Senior Laboratory Assistant, Scientific and Educational Center of Molecular Genetic Technologies, Volgograd State Agrarian University (RF, 400002, Volgograd, Prospect Universitetsky, 26), tel. 8 (905) 063-27-17, email: dimasharonov@lenta.ru

\section{Информация об авторах}

Антонов Валерий Алексеевич, и.о. директора Научно-исследовательского института гигиены, токсикологии и профпатологии (РФ, 400048, г. Волгоград, ул. им. Землячки, 12,), доктор медицинских наук, тел. 8 (8442) 78-62-57, email: antonov@rihtop.ru

Кимсанбаев Ойбек Хужамуратович, эксперт по региональному развитию проектов компании «Ajlan and Bros. Holding group». United Arab Emirates, (United Arab Emirates, Unit 03-OF-02-03-OF18, Level 3, Gate Village Building 08, Dubai International Financial Centre, Dubai) доктор сельскохозяйственных наук, профессор, тел. +966545101367, e-mail: newsbek@mail.ru

Подковыров Игорь Юрьевич, кандидат сельскохозяйственных наук, доцент по кафедре «Садоводства, селекции и семеноводства» Волгоградского государственного аграрного университета (РФ, 400002, г. Волгоград, пр-т Университетский, 26), тел. 8 (8442) 41-17-75, email: agrosad@,inbox.ru

Приходько Светлана Алексеевна, ведущий специалист Научно-образовательного центра молекулярно-генетических технологий Волгоградского государственного аграрного университета (РФ, 400002, г. Волгоград, пр-т Университетский, 26), тел. 8 (961) 679-07-22, email: bobls@,mail.ru

Шаронов Дмитрий Сергеевич, старший лаборант Научно-образовательного центра молекулярногенетических технологий Волгоградского государственного аграрного университета (РФ, 400002, г. Волгоград, пр-т Университетский, 26), тел. 8 (905) 063-27-17, email: dimasharonov@lenta.ru

DOI: 10.32786/2071-9485-2021-02-03

\section{PRODUCTIVITY OF USING THE MOISTURE OF WHITE CABBAGE DURING IRRIGATION IN THE VOLGA-DON INTERFLUVE}

\author{
A. D. Akhmedov, R. Yu. Abduova \\ Volgograd State Agrarian University, Volgograd
}

Received 08.02.2021

Submitted 09.04.2021

\section{Summary}

The article presents the results of a study when growing cabbage on light chestnut soils of the VolgaDon interfluve. Based on the data obtained, the dependence of the productivity of cabbage with drip irrigation, depending on various doses of fertilizers, was established. A graph of the dependence of the productivity of cabbage on the change in the coefficient of water consumption and total water consumption was built. The data obtained can be recommended for use as a starting material for growing cabbage on light chestnut soils of the Volga-Don interfluve.

\begin{abstract}
Introduction. The water consumption coefficient is one of the more important indicators of the efficiency of irrigation water use. With a decrease in the water consumption coefficient, the efficiency of irrigation of fields increases accordingly. Therefore, to determine the unit of marketable cabbage production, depending on the productivity with drip irrigation, we took into account the water consumption coefficient. Object. The object of research is the coefficient of water consumption of cabbage using drip irrigation in the conditions of the Volga-Don interfluve. Materials and methods. The experiments were carried out during 2017-2019 in the farming enterprise «Individual entrepreneur «Kireev» on the territory of the Volga-Don interfluve. The soils of the plot are light chestnut. On this plot, white cabbage hybrid «Aggressor F1» was grown. A two-factor field experiment was carried out annually. At the same time, three options for the water regime of the soil, factor A (the first factor), and factor B (the second factor) included the introduction of various doses of fertilizers to obtain the planned yield of cabbage of 60,70 and $80 \mathrm{t} /$ ha were selected for the research. When growing cabbage per 1 ha, the planting density on average fluctuates around 30-40 thousand plants / ha. The expe-
\end{abstract}

